\title{
Unintended Consequences: Social Isolation in the Elderly During COVID-19
}

\section{Geoffrey Carney-Knisely ${ }^{1}$}

${ }^{1}$ College of Public Health, The Ohio State University, Columbus, $\mathrm{OH}$

Corresponding Author: Geoffrey Carney-Knisely, 1841 Neil Avenue, Columbus, OH 43210, (802)578-8503, geoffrey.carney-knisely@osumc.edu

Submitted December 14, 2020 Accepted May 6, 2021 Published June 21, 2021 https://doi.org/10.18061/ojph.v4i1.8066

My mother's face paused on the screen-again. As our call reconnected, the beeping EKG machine filled the silence. I sat in the surgical intensive care unit at The Ohio State University Wexner Medical Center trying to help my mother say goodbye to her mother over a video call. My grandmother fell, breaking her hip and suffering a heart attack during surgery. Hospital policy did not allow additional visitors; today might be my mother's last chance to say goodbye.

As of February 19, 2021, nearly 500000 Americans have died from (coronavirus disease 2019) COVID-19,1 many without family members in their final moments. In Ohio, 52\% of COVID-19 related deaths occurred in long-term care facilities, exceeding the national median of $37 \% .^{2}$ Policies restricting nursing home access were adopted to protect some of the country's most vulnerable populations. These policies have come at a great cost. It does not have to be this way.

Though my grandmother survived her visit to the SICU, her recovery was uphill. My visits were phone calls while peering through her nursing home window. I witnessed her slow daily decline. Her dementia worsened. She lost weight until she weighed just 90 pounds.

Her challenges are not unique. Social isolation has harmed elderly Americans; it is associated with an increased risk of all-cause mortality, a risk that may rival or exceed that posed by smoking or obesity. ${ }^{3}$ Further, loneliness has been associated with higher rates of depression and a 50\% increased risk of developing dementia. ${ }^{3}$ Prior to the pandemic, one-quarter of community-dwelling adults were considered socially isolated. ${ }^{3}$ Lockdown policies exacerbate this challenge.

What can we do differently? What can we do to protect the most vulnerable from both coronavirus and social isolation? Part of the answer is following public health guidelines: universal mask wearing, proper hand hygiene, and maintaining social distancing. Despite the US Centers for Medicare and Medicaid Services guidance for long-term care facilities in March 2020 restricting visitor access, many outbreaks still occurred, ${ }^{4}$ suggesting introduction of coronavirus into facilities by staff. This is compounded by low adherence to infection control practices among staff, with nearly one-third failing to wear a mask. ${ }^{5}$ Enforcement of guidelines will help to reduce community spread of COVID-19 and allow nursing homes to safely loosen some restrictions.

Another part of the answer is for long-term care facilities to promote social interactions for residents, whether physically distanced activities with other residents or through technological venues. Programming that encourages physical activity while maintaining distance can improve physical and mental health. This pandemic highlighted challenges for mental health services for older adults, and we must emphasize routine and crisis psychiatric services. Increased use of screening tools and of online psychological services could benefit our elders.

We have devastated an already marginalized elderly population. Our response to the pandemic should not render lives devoid of human interaction. We need to alter our policies so that we can continue to protect elderly Americans and prevent rising rates of physical and mental health conditions in nursing homes across the country.

\section{REFERENCES}

1. Centers for Disease Control and Prevention. COVID data tracker. Accessed February 21, 2021.

https://covid.cdc.gov/covid-data-tracker

2. Kaiser Family Foundation. State COVID-19 data and policy actions. Accessed February 21, 2021. 
https://www.kff.org/coronavirus-covid-19/issue-brief/state-covid-19data-and-policy-actions/\#longtermcare

3. National Academies of Sciences, Engineering, and Medicine. The National Academies Press; Washington, D.C.: 2020. Social isolation and loneliness in older adults: opportunities for the health care system.

4. Chen MK, Chevalier JA, Long EF. Nursing home staff networks and COVID-19. Proc Natl Acad SCI U S A. 2021;118(1).

https://doi.org/10.1073/pnas.2015455118

5. Au JKL, Suen LKP, Lam SC. Observational study of compliance with infection control practices among healthcare workers in subsidized and private residential care homes. BMC Infect Dis. 2021;21(1):75.

https://doi.org/10.1186/s12879-021-05767-8 